\title{
Colestasis intrahepática benigna recurrente, un reto diagnóstico
}

\section{Recurrent Benign Intrahepatic Cholestasis is a Diagnostic Challenge}

\author{
Pedro Sánchez Márquez, MD, ${ }^{1}$ Mario H. Rey Tovar, MD, ${ }^{2}$ Martín A. Garzón, MD, ${ }^{2}$ Tatiana Echeverry, MD. ${ }^{3}$
}

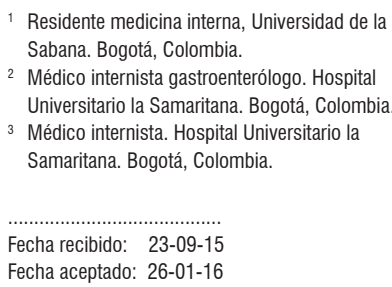

\begin{abstract}
Resumen
La colestasis hepática incluye una gran variedad de desórdenes que pueden comprometer la vía intra o extrahepática, requiriendo para su diagnóstico una asociación de hallazgos clínicos, bioquímicos, imagenológicos y en algunos casos, patológicos. Se describe el caso de un paciente que presenta episodios intermitentes y autoresolutivos de ictericia recurrente asociados con dolor abdominal y prurito intenso, en quien se encuentra durante los episodios de agudización un patrón colestásico intrahepático que se resuelve completamente durante los episodios de remisión.
\end{abstract}

Palabras clave

Colestasis, colestasis intrahepática benigna recurrente, colestasis intrahepática familiar progresiva, ictericia, prurito.

\begin{abstract}
Hepatic cholestasis includes a large variety of disorders which can compromise the intrahepatic and extrahepatic pathways. Diagnosis requires a combination of clinical, biochemical, imaging, and sometimes pathological, findings. We describe the case of a patient with intermittent episodes of jaundice which resolved by themselves but which were and decisive associated with abdominal pain and severe itching. These episodes occurred during exacerbation of the intrahepatic cholestatic pattern but completely resolved during episodes of remission.
\end{abstract}

\section{Keywords}

Cholestasis, benign recurrent intrahepatic cholestasis, progressive familial intrahepatic cholestasis, jaundice, pruritus.

\section{INTRODUCCIÓN}

La ictericia es una forma común de la enfermedad hepatobiliar (1) que puede presentar una variedad de desórdenes incluyendo sobreproducción de bilirrubinas, alteraciones en la conjugación, obstrucción biliar e inflamación hepática.

La colestasis representa un síndrome clínico y bioquímico causado por una alteración en el flujo de la bilis debido a una obstrucción del tracto biliar o una alteración en la captación, conjugación o extracción de ácidos biliares (2); puede ser intrahepática si el compromiso en la excreción biliar tiene lugar entre el citoplasma hepatocelular y los ductos biliares de mediano tamaño (hasta $400 \mu \mathrm{m}$ de diámetro) o extrahepática cuando compromete los ductos biliares mayores, incluyendo el conducto hepático y la vía biliar común (3).

El diagnóstico se realiza según los hallazgos clínicos y se confirma una vez se encuentran alteraciones en la bioquímica hepática y obstrucción en la vía biliar por imágenes diagnósticas requiriendo, en algunas ocasiones, confirmación con biopsia hepática. Clínicamente, independiente 
de su origen, la colestasis se manifiesta de forma predominante como ictericia y prurito, los cuales afectan la calidad de vida de los pacientes.

\section{REPORTE DE CASO}

Hombre de 55 años, soltero, agricultor, quien ha presentado semestralmente episodios de ictericia generalizada asociada con dolor abdominal de predominio en hipocondrio derecho, tipo picada, no irradiado, náusea, coluria y prurito; los episodios son de inicio y resolución progresiva, sin eventos desencadenantes o atenuantes, con desaparición completa de los síntomas entre episodios. Tiene antecedente personal de ingesta de alcohol, <30 g semanales durante 30 años, hospitalizaciones previas por síndrome ictérico, discapacidad física auditiva desde la infancia y colecistectomía abierta por colelitiasis (2003). Al examen físico, el paciente está en aceptable estado general con ictericia mucocutánea generalizada, sin signos de hepatopatía crónica o hipertensión portal.

Durante los episodios previos de ictericia y remisión se realizaron múltiples estudios, como colangiopancreatografía retrógrada endoscópica y ecografía abdominal total, que reportaron ausencia quirúrgica de vesícula biliar sin alteraciones de la vía biliar intra o extrahepática, y paraclínicos con patrón colestásico de ictericia durante la agudización y normales durante la remisión. Se tomó biopsia hepática (2003) que mostró hígado con arquitectura conservada, colestasis hepatocitaria y canalicular pericentral con histiocitos, sin cambios inflamatorios en los conductos biliares.
Por el patrón colestásico persistente se inició estudio, los últimos exámenes presentaron los siguientes resultados: hemograma normal; PT 13,7/12,3; PTT 27,1/25.2; INR 1,11; bilirrubina total $30,1 \mathrm{mg} / \mathrm{dL}$; bilirrubina directa 19,3 $\mathrm{mg} / \mathrm{dL}$; fosfatasa alcalina $407 \mathrm{UI} / \mathrm{L}$; aminotransferasas normales en límite superior, ALT 31,2 U/L y AST 41,3 U/L; hipoalbuminemia en $2,41 \mathrm{mg} / \mathrm{dL}$; función renal normal; serología para hepatitis $\mathrm{B}$ y $\mathrm{C}$ no reactivas; hierro total, transferrina, TIBC, TSH y ceruloplasmina normales; Alfa feto proteína y Ca 19-9 negativos, AMA y ANA negativos; ASMA positivos 1:80 diluciones, ENAS y anti-LKM negativos.

Se realizó una tomografía de abdomen que evidencio hígado con infiltración grasa sin evidencia de lesiones focales, vía biliar intra y extrahepática normal, ausencia quirúrgica de la vesícula biliar; bazo, páncreas, glándulas suprarrenales, riñones y sistemas colectores de apariencia usual; retroperitoneo sin evidencia de alteración (figura 1).

Se realizó una nueva biopsia hepática que evidenció arquitectura hepática conservada, con severa colestasis intrahepática de localización pericentral, cambios degenerativos hepatocíticos vaculados con pigmento biliar, sin evidencia de lesión de los espacios porta (figuras 2 , 3 y 4 ).

Se concluyó, en ausencia de cirrosis, con resultados de la biopsia y paraclínicos de control, que los episodios de ictericia recurrente corresponden colestasis intrahepática benigna.

\section{REVISIÓN DE LA LITERATURA}

La colestasis intrahepática benigna recurrente (BRIC) es una causa atípica de colestasis. Fue descrita en 1959 por

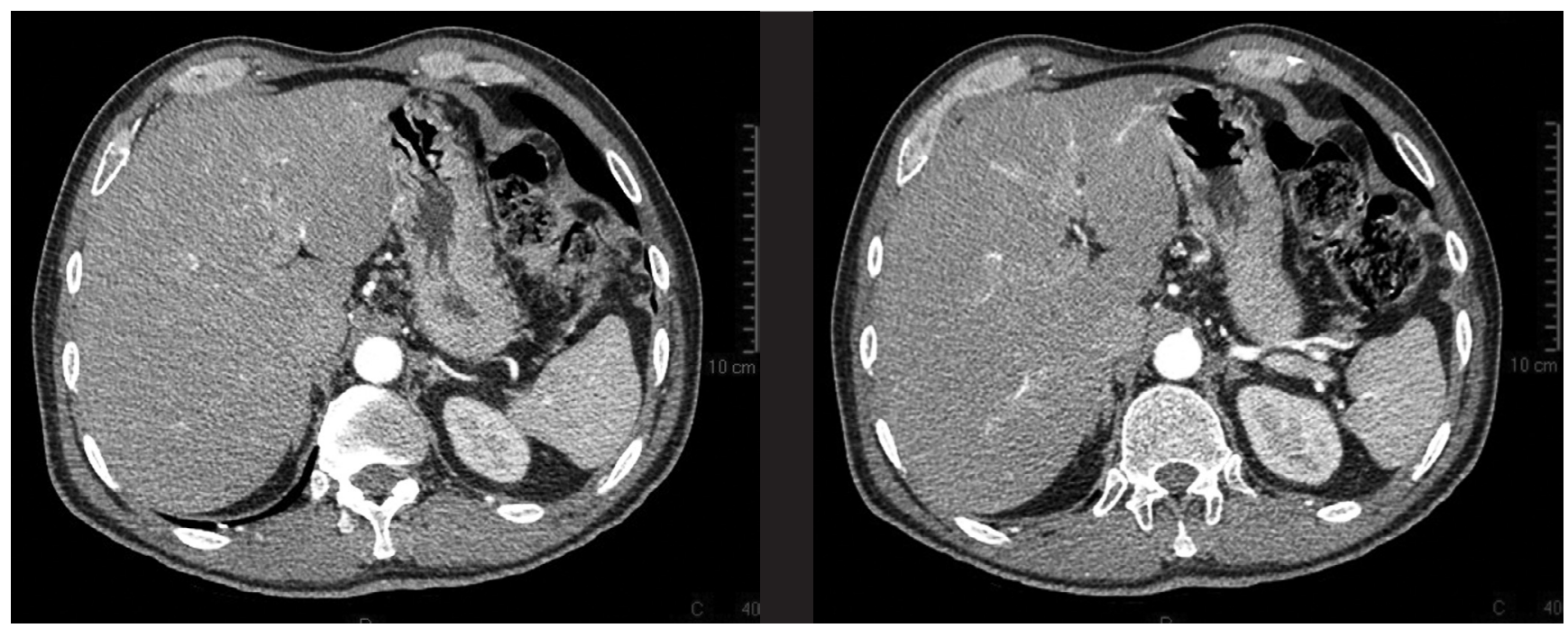

Figura 1. TAC contrastada de abdomen. Corte axial. Se observa el hígado con infiltración grasa, sin evidencia de lesiones focales, ausencia de vesícula biliar, vía intra y extrahepática normal. 


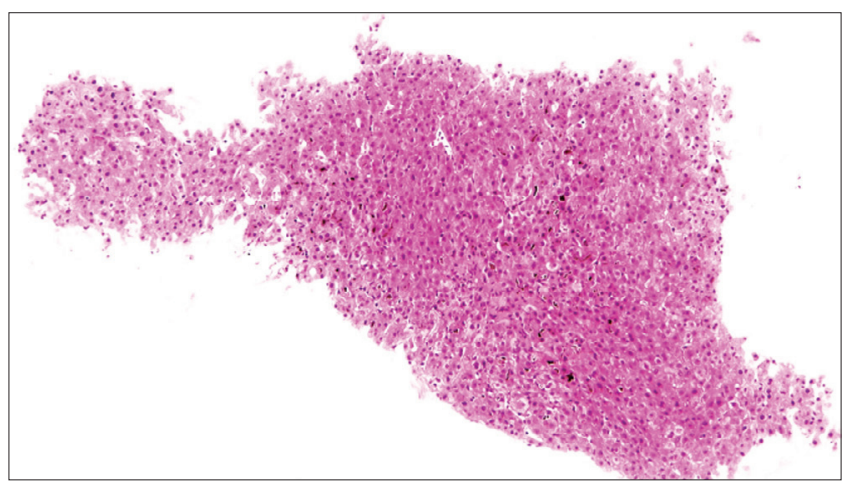

Figura 2. Biopsia hepática, corte de bajo poder del parénquima hepático. Tinción de HE.

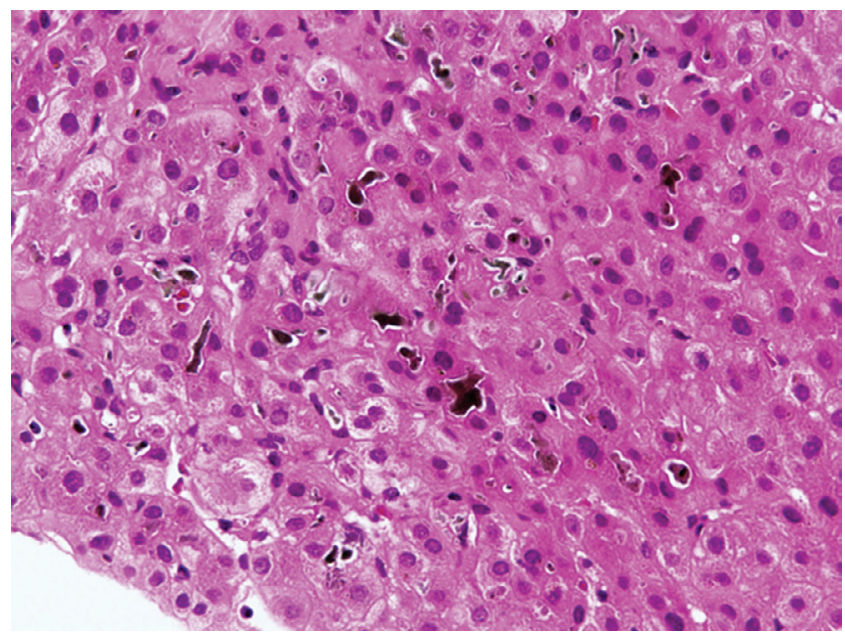

Figura 3. Biopsia hepática, corte de bajo poder. Tinción de HE. Arquitectura hepática conservada.

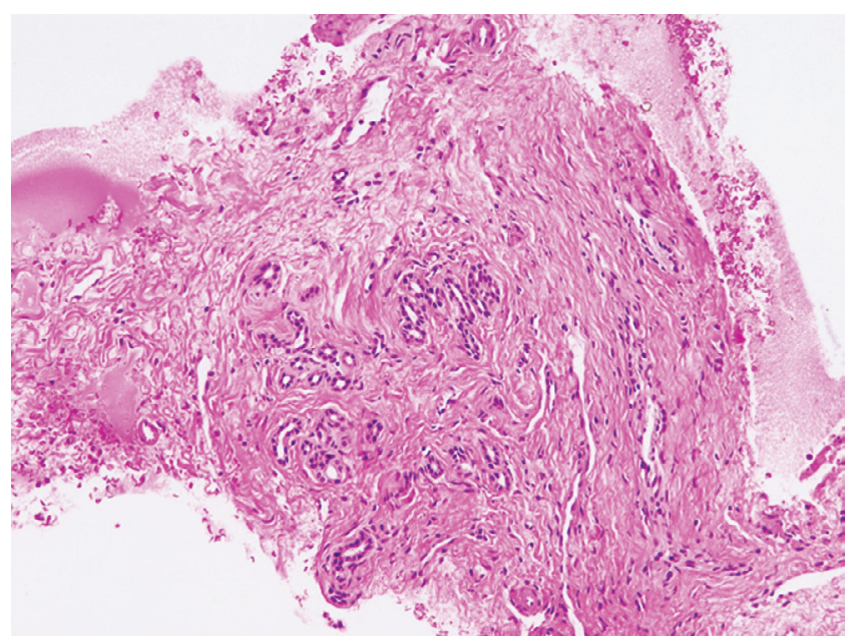

Figura 4. Biopsia hepática, corte de alto poder. Parénquima hepático. Tinción de HE. Colestastis intrahepática pericentral. Hepatocitos vacuolados con pigmento biliar.
Summerskill y Walshe (2). Más frecuente en hombres, suele presentarse luego de la primera década de la vida, con episodios que pueden recurrir desde varios casos por año hasta 1 por década, durando de semanas a meses, resolviéndose de manera espontánea sin llevar a disfunción hepatocelular progresiva, fibrosis o cirrosis $(4,5)$.

Los criterios diagnósticos establecidos por Luketic y Shiffman incluyen (6): 1 . Antecedente de mínimo 2 episodios de ictericia con 1 periodo asintomático intercrítico de meses a años; 2. Paraclínicos consistentes con colestasis intrahepática, incluyendo elevación de la fosfatasa alcalina, hiperbilirrubinemia conjugada, GGT y aminotransferasas en límite superior; 3. Prurito intenso secundario de colestasis, aunque puede estar ausente en el $25 \%$ de los casos; 4. Ausencia de otros factores etiológicos conocidos de colestasis; 5 . Vías biliares intra y extrahepática de morfología normal demostrada mediante colangiopancreatografía retrógrada endoscópica; y 6. Biopsia hepática que muestre colestasis centrilobular. Todos estos cambios se deben resolver en los periodos intercríticos.

Tiene un patrón de herencia autosómico recesivo con penetrancia incompleta, se asocia con mutaciones en los genes involucrados en la colestasis intrahepática familiar progresiva: ATP8B1 (I) y ABCB11 (II), localizados en el cromosoma 18 (18q21-22) y 2 , respectivamente (7).

En los pacientes con BRIC, estas mutaciones se asocian con alteraciones en las ATPasa que intervienen en el trasporte de cationes como cobre, calcio, sodio y potasio, así como en la correcta posición de los fosfolípidos que componen las membranas celulares. Su modificación se vincula con cambios en la permeabilidad de la membrana, llevando a trastornos en el trasporte celular y como consecuencia, la reducción en la secreción de ácidos biliares en nivel hepático, secreciones exocrinas pancreáticas y disminución en la reabsorción de sales biliares en nivel intestinal, todo lo cual lleva al aumento en la pérdida de estas sales, característico de los pacientes con BRIC $(8,9)$.

Hasta el momento, no hay un tratamiento específico disponible para prevenir o reducir la duración de los ataques; el tratamiento primario se basa en aliviar los síntomas hasta que resuelva de forma espontánea cada episodio. Se ha usado la colestiramina y el ácido ursodesoxicólico por su efecto protector sobre las membranas celulares al prevenir la citólisis y la apoptosis inducida por ácidos biliares, adicional al efecto inmunomodulador al disminuir la liberación de IL-2, IL-4 e interferón gamma (10).

El pronóstico es bueno sin progresión a cirrosis; con la resolución de un ataque el prurito se resolverá rápida y completamente, con mejoría de la ictericia y de las anormalidades en las enzimas hepáticas $(4,5)$. 


\section{REFERENCIAS}

1. James W, Aaron M. Diagnostic Approach to the Patient with Jaundice. Prim Care Clin Office Pract. 2011;38:469-482.

2. Ken D, Vinay S, Walid S. Atypical causes of cholestasis. World J Gastroentero. 2014; July 28; 20 (28): 9418-9426.

3. Pérez T, López P, Tomás E., et al. Diagnostic and therapeutic approach to cholestatic liver disease. Rev Espa Enferm Dig. 2004;96:1:60-73.

4. Luketic VA, Shiffman ML. Benign recurrent intrahepatic cholestasis. Cli Liver Dis 2004;8:133-49.

5. Van der Woerd WL, van Mil SW, et al. Familial cholestasis: Progressive familial intrahepatic cholestasis, benign recurrent intrahepatic cholestasis. Best Pract Res Clin Gastroenterol. 2010;24:541.
6. Renard R, Geubel AP, Benhamou JP. Bening recurrent intrahepatic cholestasis. J Clin Gastroenterol. 1989;11:546-51.

7. Anshu Srivastava. Progressive Familial Intrahepatic Cholestasis. J Clin Exper Hepatol. 2014;3:4:25-36.

8. Minuk GY, Shaffer EA. Bening recurrent intrahepatic cholestasis. Evidence for an intrinsic abnormality in hepatocite secretion. Gastroenterology. 1987;93:1187-93.

9. Bijleveld CM, Vonk RJ, Kuipers F, Havinga R, et al. Bening recurrent intrahepatica cholestasis: Altered bile acid metabolism. Gastroenterology. 1989;97:427-32.

10. Maggiore G. Efficacy of ursodeoxycholic acid in preventing cholestasic episodes in a patient with bening recurrent intrahepatic cholestasis. Hepatology. 1992;16:504. 